\begin{tabular}{|c|c|}
\hline ב & $\begin{array}{c}\text { International Journal of Current Research } \\
\text { and Academic Review }\end{array}$ \\
\hline $\begin{array}{l}\mathrm{T} \\
\mathrm{NT} \\
\mathrm{RS}\end{array}$ & 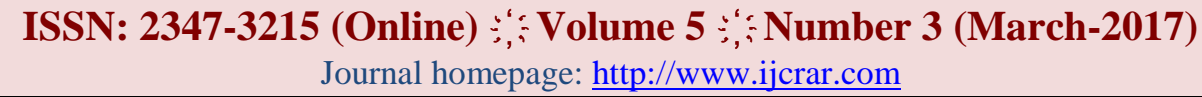 \\
\hline
\end{tabular}

doi: https://doi.org/10.20546/ijcrar.2017.503.001

\title{
Effectiveness of Educational Program on Diabetic Adolescents Knowledge toward Self- insulin Shot Technique in AL- Fahiaa Specialist Center at Al- Basra City
}

\author{
Noor Salah Shreef and Fatima W. Khudair*
}

University of Kufa, College of Nursing, Iraq

*Corresponding author

\section{Abstract}

Diabetes mellitus (DM) is one of more inveterate disease with wasteful complication, and the middle east is likely to onus one of the greatest problems of diabetes worldwide in the coming year. To measure the effectiveness of an educational program on adolescents knowledge about insulin shot technique. A research control trial was carried out at AL-fahiaa specialist to center in AL- fahiaa general hospital from $1^{\text {st }}$ November, 2015 until $21^{\text {th }}$ July, 2016. Non-probability sampling technique (purposive sample) base to criteria (diabetes mellitus type 1, used insulin injection and ability to read and write).The educational program was designed to improve patient knowledge toward insulin shot technique. This program was implemented through four steps: pre - program, program intervention, post test program and follow up. The educational activities employed several teaching and learning strategies. A questionnaire was designed as a tool for data collection for the purpose of the study. It was composed of three major parts, the first one concerning demographic data, medical history and third was divided into general information about DM (15) item and insulin shot technique administration questions (14) item. Data were collected and analyzed through the application of the descriptive statistical means (Frequency and percentage) and inferential statistical data analysis approach (one - way analysis of variance ANOVA test). Patients who had participated in the study had benefited from the implementation of educational insulin shot technique program and change had occurred to their knowledge about insulin administration technique (a mean scores of pre-test were improved in post-test I and post- test II). Insulin shot technique education program had had a positive effect on adolescents knowledge related to insulin shot technique. The program should include diabetes mellitus in school curriculum.
\end{abstract}

\section{Article Info}

Accepted: 28February 2017

Available Online: 20 March 2017

\section{Keywords}

Diabetic adolescents, Diabetes Mellitus (DM), Self-insulin

\section{Introduction}

Diabetes Mellitus (DM) is one of more inveterate disease with wasteful complication, and the middle east is likely to onus one of the greatest problems of diabetes worldwide in the coming years (Yekta et al., 2011). According to WHO it is estimated (2007) that 190 million people with diabetic disease in the world, also 330 million people likely to diabetes disease in the 2025 (Lorenzo et al., 2007). Diabetes is one of main causes of death and disability worldwide (Neelammakol, 2008). Globally, diabetes is chronic disease and is new growing as an epidemic in all developed and developing countries (Zimmet, 1999). 
The developed areas of the world, such as the United States of America have high Prevalence rates of Diabetes mellitus estimated 29.1 million people with diabetic disease or $9.3 \%$ of the all population in USA in 2012, about 1.25 million children and adults have type one of diabetic disease (ADS, 2012). Diabetes Mellitus is rapidly growing in the world, it is about 415 million diabetic people in the world in the 2015 (IDF, 2016).According to the World Health organization found 1.5 million people died as a result of diabetes in the 2012, making it 8th cause of death in the world (WHO, 2013).

Estimated diabetes prevalence in the Canadia is 3.4 million patient or $9.3 \%$ of population in the 2015 and expected increased prevalence of diabetes in the 2025 to the 5 million patients(CAS, 2016).Arab gulf countries such as Qatar, Kuwait and Saudi Arabia are in the top 10 of countries injuries of diabetes mellitus (IDF, 2010). According to the latest statistical records of the diabetes mellitus in Iran, it's estimated that the spread rate of diabetes disease 2.3\% of people (Hazavehei et al., 2007). It is estimated that Egypt occupies 9th rank among the countries that have diabetes disease in the 2015, more than 9 million Egyptians (13\% of the population) will have diabetes (Naglaa Abdo, 2010). The prevalence rate of diabetes in Iraq is $6.1 \%$ of population. This average is equally divided between male and female (WHO, 2006). Latest statistic reports of the Diabetes mellitus of Basra, it is estimated that the prevalence of diabetes is $12 \%$ of the population (Al-Basra Health Directorate, 2010).

\section{Objective of the study}

To assess the adolescents level of knowledge about insulin shot technique.

To measure the effectiveness of an educational program on adolescents knowledge about insulin shot technique.

To identify the relationship between adolescents knowledge about insulin shot technique and their sociodemographic characteristics of age, gender, educational level and residency area.

\section{Definitions of terms}

\section{Effectiveness: Theoretical definition}

The extent to which programs outcomes can be determined to present its impact on specific participant behavior (Encyclopedia \& dictionary of medicine, 2009).

\section{Operational definition}

The degree to which the actual outcomes of educational program can be determined through computation of patients knowledge scores about management of insulin shot technique aspects, such as definition of DM., types of DM, signs and symptoms, complications, tests used diagnosis of diabetes, sites of injection area, equipment of injection and steps of technique that should be increased after educational intervention.

\section{Educational program}

\section{Theoretical definition}

An instructional and interventional design, which is concerned with the development of special or general abilities, which facilitates psycho-motor learning capabilities (Encyclopedia \& dictionary of medicine, 2009).

\section{Operational definition}

Insulin shot technique oriented program which is classified into three major aspects of definition of DM, types of DM, signs and symptoms, complications, tests used to diagnosis of DM, sites of injection area and steps of injection.

\section{Knowledge}

\section{Theoretical definition}

Knowledge is a knowing realization or grasp of some body or something such as facts, information, characterization, or skills, which is gained during experience or education by cognitive, detection or studying (Souza, 2000).

\section{Operational definition}

The degree to which the diabetic patients perceived principles and information concerning insulin shot technique.

\section{Adolescent}

\section{Theoretical definition}

Adolescence is interval in human growth and development that happens after childhood and before puberty, from ages 12 to 18 (WHO, 2016). 


\section{Operational definition}

Patients with diabetes mellitus type 1 aged 12-18 years who attended at Al-Fahiaa specialist center at AL- Basra city for treatment and follow up.

\section{Review of literature}

\section{Diabetes mellitus}

The term diabetes mellitus (DM) describes a defect of metabolism of different etiological agents identified by high blood sugar with upset carbohydrate, fat and protein causing by defect in insulin secretion, insulin action or both (Njolstad, 2003). It is a chronic disease, it happens when the pancreas cannot product insulin, or the body is reluctant to produce the insulin. This leads to an increased glucose in the blood, it is called hyperglycemia (WHO, 2016). Diabetes caused failure growth and delay to sexual development but control to the diabetic can prevent those problems (Terri Kyle, 2013). D.M. is a serious health problem throughout the world and its prevalence is increasing rapidly (Lewis, 2011).

\section{Types of DM}

Type 1 diabetes: This type occur from the autoimmune unrest of the $\beta$ cells in the pancreas, it is responsible to produce insulin (Kristina Rother, 2007). People have type one diabetes, lack of endogenous insulin production (Mastrandrea, 2009). It affects approximately 5\% to $10 \%$ of people with disease (Devendra, 2004). This type shows the ability of patient to accept it genetically or may be also exposed to one or several environmental or acquired factors, such as chemicals, viruses, or other toxic agents (Terri Kyle, 2013).

Type 2 diabetes: It is most common in the adult but in last years it is found in the children and adolescents with diabetes type 2, diabetes type 2 makes up for ninety percentage of all situations of D.M. (WHO, 2012). Type 2 diabetes characterized by defect of insulin secretion with contributed from insulin resistance (WHO, 1999). It is believed the body tissue is resist of insulin. However, the specific defect is unknown (Wikipedia, 2016). This type can be occur as result of obesity or lack of activation and found family history in this disease (Risérus, 2009).

\section{Other types of D.M}

Gestational diabetes usually occur during pregnancy, around 24th week. Many women can developed it to type 2 diabetes but it can prevented to develop during regular blood glucose level as normal (Thomas A. Buchanan and Anny H. Xiang, 2005). It occurs in about $2-10 \%$ of all pregnancies (NDS, 2011).

\section{Signs and symptoms of D.M}

The classical symptom of diabetic is polyuria (frequent urination), polyphagia (increased hunger), polydipsia (Excessive thirst) and rapid weight loss this symptom can develop rapidly in type 1 diabetes but it needs several years to develop in type two diabetes (Cooke, 2008).

\section{Management of D.M}

D.M. is chronic disease, in this disease is there unknown cure except in rare cases (Buse, 2009). Management focus on keeping blood glucose level as normal as can accomplish with healthy diet, regular physical exercises, normal body mass index and used appropriated medication (depended to types of diabetes) (Inzucchi, 2012).

Medication: Diabetic medications work to reduce glucose in the blood, different numbers of medication depend on types of diabetes, T1D used insulin injection and T2D used oral medication (ADA, 2016).

\section{Insulin therapy}

Insulin is a hormone made by pancreas that allows body to use sugar from carbohydrates in food or store in the pancreas and use it in the future. Cell needs insulin for energy, after meal the blood sugar levels so high the cell in the pancreas (beta cell) is signal to secretion insulin in the blood stream, insulin absorbs sugar from blood stream. Insulin keeps blood sugar level as normal (Joslin Diabetes Center, 2014). Patient with T1D needs insulin injection because his body stops secretion of insulin and some patient with T2D use it (Simmons, 2016).

\section{How taking insulin}

Insulin is given by injection under the skin (known subcutaneous injection SQ) because insulin is protein, stomach acids digest it is like it the protein in food. Usually injected insulin under to the skin to upper arm (little slower absorption), thigh (Even more slowly absorption), buttocks (slowest) and abdominal (faster), most diabetic patients injection insulin 2-4 times a day. Insulin kind and dose may also change every day, depending on life style of patients (Davel, 2014). 


\section{Insulin types}

1-Rapid-acting insulin

2-Regular or Short-acting insulin

3-Intermediate - acting insulin

4-Long-acting insulin

\section{Insulin shot technique}

Effectiveness of insulin injection in diabetes depends on the right injection techniques with other factors. Correct insulin injection technique are essential to control blood glucose and avoid complications of diabetes. The patients and care giver must understand injections and injection technique (Sanjay Kalra, 2012). About 1.2 million Indians used insulin injection (Prasad, 2012).

\section{Steps insulin injection technique}

Before injection must bring out insulin of refrigerator prior $30 \mathrm{~min}$ of injection and sure the insulin is at room temperature, choose the right injection site (Prasad, 2012).

1-Hand washing for prevent infection

2-Check insulin characteristic (type of insulin and expiration data) (American diabetes Association, 2004).

3-Mix insulin (rolled insulin between hands) without shaking

4-Clean top of rubber insulin vial with alcohol.

5-Inject air to the insulin vial (must amount of air equal to amount of insulin to avoid vacuum) (Prasad, 2012).

6-Removed bubble of air from syringe caused minimized injection pain (Richard Dolinar, 2009).

7-Draw up amount of insulin to complete prescribed dose (ADA, 2004)

8 -Cover the needle to the moment of administration (ADA, 2004).

9- Clean injection site with alcohol and allow dry (evaporated alcohol before injection to help reduced pain injection) (American diabetes Association, 2004).

10-Pinch a fold of skin between thumb and index finger to avoid inject insulin in muscle caused intramuscular injection painful and insulin absorption fast result hypoglycemia (Richard Dolinar, 2009).
11- Inject insulin at 45 angle to children and thin individuals or 90 angle (H. Peter Chase, 2010).

12-Aspirate fluid back into syringe to check for blood return (Sociedade Brasileira de Diabetes, 2007).

13-After injection, wait 5-10 second to removed needle to avoid leakage (Royal college of nursing, 2012).

14-pressure to injection site without massage (Peter Chase, 2010).

\section{Materials and Methods}

\section{Design of the study}

A research control trial was carried out during this study in order to attain the early stated objectives. The study started from 1st November, 2015 until 21th July, 2016.

\section{Setting of the study}

The study conducted at Al-Fahiaa specialist Center.

\section{Study sample}

A non-Probability sampling technique (Purposive Sample) based on criteria of patients with type 1 diabetes, using insulin injection and ability to write and read. The sample was of (40) diabetic adolescent, those who attend Al-Fahiaa general hospital / Al-fahiaa specialist center for therapy or checkup.

\section{The study instrument}

The questionnaire was applied as a mean of data collection that was comprised of three main parts.

\section{Part I: Demographic data}

A demographic data paper, contained (7) paragraphs, which include age, sex, level of education, regency area, number of family, child order to the family and family income.

\section{Part II: Medical history}

This part consisted of (6) item, family history, type of insulin used, how administrated insulin shot, Source of knowledge to word insulin shot, how many time administrated insulin at day and onset of diagnosis. 
Part III: Assessment of adolescents' knowledge concerning the insulin shot technique

This part is comprised of (15) item about to general information about D.M. and (14) item concerning to insulin shot technique.

\section{Data collection}

Data collection was executed during the use study administration and the implementation of the constructed Insulin shot technique educational program for the period from 3rd April to 3rd June, 2016. Fifteen minutes to complete the answer of the questionnaire.

Data collection included technique;

1-prior approval was obtained from all adolescent who participated in the sample before collection data.

2-All adolescents exposure to pre-test purpose to assess their knowledge about insulin shot technique.

3-All adolescents were exposure to the insulin shot technique educational program.

4-After introduced of the program, all adolescents exposure to post-test immediately.

5-After two weeks, all adolescents were exposure to post-test II

\section{Statistical analysis}

Appropriate statistical methods are used in order to assess and analyze the results of the study which include frequencies, percentage, mean and standard deviation. Analysis of variance test (ANOVA) used to compare pre-test, post-test I and post-test II score.Chi-square test to compare frequencies.

\section{Limitations of the study}

This study faces some limitations during its process: lack of national studies that are concerned with knowledge insulin shot technique.

\section{Results and Discussion}

The age of the studied group ranged $12-18$ years. Males represented $(62.5 \%)$ of the 40 participants, $(55 \%)$ of adolescents with primary school graduated. Majority of the studied group, $(85 \%)$, of urban residence $(25 \%)$ of adolescents have family number of 6 persons. About one third of adolescents rank in fourth order. In addition, $80 \%$ of the sample is with sufficient income.

As it shown in table $1,70 \%$ of sample has diabetic relatives. In relation to the adolescents family $82.5 \%, 85 \%, 80 \%$ have no diabetes ( fathers, mother and siblings) respectively. (95\%) of sample take insulin in accurate time and accurate dose. More than two third, $62.5 \%$ of diabetic adolescents have complication in site of injection. According to the type of insulin $65 \%$ of sample use rapid and short acting. More two third(77.5\%) of sample inject themselves. $60 \%$ of sample take source of knowledge to insulin shot from medical staff. $42.5 \%$ of sample use insulin shot four times per day. Two third of adolescents are with age 11-15 year when they diagnosed.

The result of comparison describes that step 1, step 2, step 3, step 6, step 7 and step 8 do not affect the program in these steps but other steps show improvement for knowledge throughout the implementation of the education program (Table 2).

Regarding to adolescents knowledge concerning general information about diabetes, it appears that adolescents have correct response to all items. This indicates the desire to learn in this age group and raise their awareness about the disease. Concerning definition of diabetes, $70 \%$ of adolescents define the diabetes as a hereditary disease, this result agrees with K.P. Mashige, who found the majority of study sample define the diabetes as a hereditary disease (Mashige, 2008). In relation to normal range of blood sugar, $60 \%$ of adolescents answer it correctly. Regarding type one diabetes, $80 \%$ of adolescents know correct answer about type 1 diabetes which have prevalence in childhood. Concerning cause of diabetes, $95 \%$ of adolescents believe that a lack of insulin caused diabetes, this is similar to E. Mbuga, who reported majority of study sample answer correctly (Mbuya, 2014). 97.5\% of adolescents have correct answer about psychological status affected diabetes mellitus, also $70 \%$ of adolescents answer the diabetes affected blood pressure. This result is similar to S. Al Bimami, she found more than $60 \%$ of study sample were aware that diabetes affect blood pressure (AlBimami, 2015). $75 \%$ and $92.5 \%$ of them adolescents answer the items of T1DM and symptoms of hypoglycemia by always. 95\%, 87.5\%, 95\% and 95\% of them adolescents answer the items of symptoms of hyperglycemia, hypoglycemia more dangerous than hyperglycemia, overdose of insulin and method of insulin injection be always respectively. Regarding to site of injection, 
$97.5 \%$ of adolescents answer always only $2.5 \%$ answer sometimes. About diagnosis of D.M., $92.5 \%$ of adolescents chose always. $90 \%$ of adolescents chose always about diabetes caused retinopathy. This note increases in correct answer in several items of different pre-tests.

All study sample(100\%) answer correctly about overdose of insulin cause hypoglycemia, while Badruddin in her study found only $35 \%$ of study sample answer the over dose of insulin caused hypoglycemia (Badruddin, 2002). Concerning method of insulin injection, all adolescents answer correctly. This result agrees with A. Mushataq, he found $65 \%$ of study sample know sub-cutaneous tissue injection methods of injected insulin (Mushataq, 2006).

$95 \%$, of adolescents know diabetes caused retinopathy but Sharif Islam found $33.5 \%$ of study sample know that the diabetes caused retinopathy (Sharif Islam, 2015). The note decrease in several items concerning correct answer in different post-test I. $95 \%$ of adolescents correct answer to normal range of blood sugar. This result is consistent with S. AL-Bimami, she found most of study sample answer the normal glucose level 70-110 mgldL (AL-Bimami, 2015). Regarding complications of hypoglycemia, $90 \%$ of adolescents have correct answer, this result agrees with V. Williams, he found $94.1 \%$ answer correctly. $95 \%$ of adolescents chose correct answer about symptoms of hyperglycemia, this result is similar to V. Williams.

V. Williams found most of study sample had correct answer (Williams, 1998). More than half $(57.5 \%)$ of participants perform hand washing, this result approved by Stacciarini, he found most of sample hand washing. Most of adolescents don't clean insulin top bottle with alcohol, this result approved Stacciarini, he found all study sample (100\%) do not clean rubber top of insulin bottle by alcohol. They reported that $(52.5 \%)$ of sample inject air to the insulin bottle, this result invalidates Stacciarini, he found $68 \%$ of sample do not inject air in the insulin bottle (Stacciarini, 2009).77.5\%, 85\% and $92.5 \%$ of them adolescents answer the items of check insulin characteristic, mix insulin without shacking and removed bubble from syringe by correct answer respectively. In result, $90 \%$ of adolescents withdrawal amount of insulin to complete dose, this result approbate Tania, she found most of sample withdrawal amount of insulin is necessary to complete dose. About two third $(65 \%)$ of sample clean the skin with alcohol. This result agrees with Tania. She found $53.85 \%$ of sample clean skin. Only $55 \%$ of studied group press the skin after injection. This result is consistent with Tania, she found $57.69 \%$ of study sample press the injection site without massage (Tania Alves Canata Becker, 2011). Majority $(85 \%)$ of sample cover needle at moment of injection. Also $70 \%$ of adolescents pinch skin during injection. This result agrees with Partenent T. He found most of sample has pinch skin during insulin administration (Partenen, 2000). More than half (67.5\%) of sample inject needle at 45 degree angle. This result disagrees with Gerensea. He found most of study sample do not inject insulin syringe at 45 angle (Gerensea, 2015). Our result indicated that $50 \%$ of adolescents draw up fluid back into syringe to check for blood return. Majority $(85 \%)$ of sample wait five seconds until withdrawing the needle. Our analysis revealed that an increase in adolescents' knowledge in several items in different to pre-test. This result can be interpreted by that adolescents have gain more information of educational program. Show All sample (100\%) wait five seconds to withdraw the needle, this result disagreement with Tania, she found $73.08 \%$ of sample don't waiting five seconds (Tania Alves Canata Becker, 2011). 80\%of sample recap needle at moment of administration, this result contradict Stacciarini, he found high majority $(91.7 \%)$ of sample don't recap needle at moment of administration. $92.5 \%$ of adolescents draw up fluid back into syringe to checking for blood return, this result disagree with Stacciarini, he found $65.1 \%$ of study sample don't draw up insulin back the syringe to checking for blood return (Stacciarini, 2009).

The study finding reports that indicate the answer decrease in several items. Our analysis indicated that $52.5 \%$ of sample clean skin before injection. This result is in contrast with Stacciarini. He found all sample study do not clean skin by alcohol. Also 95\% sample wait five seconds to withdraw the needle. This result disagrees with Stacciarini, he found $84.6 \%$ of study sample do not do it (Stacciarini, 2009). More than two third $72.5 \%$ of sample compress the skin after injection. 
Table.1 Distribution of the Study Sample by their Clinical history

\begin{tabular}{|c|c|c|c|}
\hline \multicolumn{2}{|l|}{ Medical history } & No. & $\%$ \\
\hline \multirow{2}{*}{$\begin{array}{l}\text { Did any one of your relative have } \\
\text { diabetes? }\end{array}$} & Yes & 28 & 70.0 \\
\hline & No & 12 & 30.0 \\
\hline \multirow{2}{*}{ Did your father have diabetes? } & Yes & 7 & 17.5 \\
\hline & No & 33 & 82.5 \\
\hline \multirow{2}{*}{ Did your mother have diabetes? } & Yes & 6 & 15.0 \\
\hline & No & 34 & 85.0 \\
\hline \multirow{2}{*}{ Did your sibling has diabetes? } & Yes & 8 & 20.0 \\
\hline & No & 32 & 80.0 \\
\hline \multirow{2}{*}{$\begin{array}{l}\text { Did you have administrated insulin shot } \\
\text { at dosage? }\end{array}$} & Yes & 38 & 95.0 \\
\hline & No & 2 & 5.0 \\
\hline \multirow{2}{*}{$\begin{array}{l}\text { Did you have administrated insulin shot } \\
\text { at time? }\end{array}$} & Yes & 38 & 95.0 \\
\hline & No & 2 & 5.0 \\
\hline \multirow{2}{*}{$\begin{array}{l}\text { Did you have complication at site of } \\
\text { shot? }\end{array}$} & Yes & 25 & 62.5 \\
\hline & No & 15 & 37.5 \\
\hline \multirow{2}{*}{ Type of insulin used mix acting } & Yes & 14 & 35.0 \\
\hline & No & 26 & 65.0 \\
\hline \multirow{2}{*}{ Rapid and short acting } & Yes & 26 & 65.0 \\
\hline & No & 14 & 35.0 \\
\hline \multirow{3}{*}{ How administrated insulin shot? } & Yourself & 31 & 77.5 \\
\hline & Parent & 8 & 20.0 \\
\hline & Sibling & 1 & 2.5 \\
\hline \multirow{2}{*}{ Source of knowledge insulin shot? } & medical staff & 24 & 60.0 \\
\hline & family & 16 & 40.0 \\
\hline \multirow{4}{*}{$\begin{array}{l}\text { How many times administrated insulin } \\
\text { per day? }\end{array}$} & one & 0 & 0.0 \\
\hline & Two & 15 & 37.5 \\
\hline & Three & 8 & 20.0 \\
\hline & Four & 17 & 42.5 \\
\hline \multirow{4}{*}{ Onset of diagnosis } & $1-4$ & 3 & 7.5 \\
\hline & $5-10$ & 8 & 20.0 \\
\hline & $11-15$ & 25 & 62.5 \\
\hline & $16-18$ & 3 & 7.5 \\
\hline
\end{tabular}


Table.2 Comparative Differences Between Pre - test, Post - test I and Post - test II Relative to the adolescents' Knowledge about Insulin shot technique

\begin{tabular}{|l|c|c|c|c|}
\hline & Pre -test & Post - test I & Post - test II & \multirow{2}{*}{ P.value } \\
\cline { 2 - 4 } & mean \pm SD & mean \pm SD & mean \pm SD & \\
\hline Step 1 & $2.27 \pm 0.90$ & $2.90 \pm 0.89$ & $2.90 \pm 0.88$ & 0.725 \\
\hline Step 2 & $2.60 \pm 0.77$ & $2.82 \pm 0.44$ & $2.82 \pm 0.54$ & 0.165 \\
\hline Step 3 & $2.72 \pm 0.67$ & $2.92 \pm 0.34$ & $2.70 \pm 0.64$ & 0.501 \\
\hline Step 4 & $1.82 \pm 0.95$ & $2.85 \pm 0.42$ & $2.60 \pm 0.74$ & $<0.001$ \\
\hline Step 5 & $2.10 \pm 0.98$ & $2.90 \pm 0.44$ & $2.80 \pm 0.56$ & $<0.001$ \\
\hline Step 6 & $2.85 \pm 0.53$ & $2.95 \pm 0.22$ & $2.85 \pm 0.42$ & 0.463 \\
\hline Step 7 & $2.87 \pm 0.40$ & $2.97 \pm 0.15$ & $2.90 \pm 0.37$ & 0.613 \\
\hline Step 8 & $2.75 \pm 0.63$ & $2.75 \pm 0.54$ & $2.67 \pm 0.61$ & 0.503 \\
\hline Step 9 & $2.35 \pm 0.92$ & $2.82 \pm 0.50$ & $2.22 \pm 0.89$ & 0.002 \\
\hline Step 10 & $2.47 \pm 0.84$ & $2.92 \pm 0.34$ & $2.75 \pm 0.63$ & 0.008 \\
\hline Step 11 & $2.45 \pm 0.84$ & $2.95 \pm 0.22$ & $2.62 \pm 0.70$ & 0.003 \\
\hline Step 12 & $2.05 \pm 0.98$ & $2.90 \pm 0.37$ & $2.47 \pm 0.84$ & $<0.001$ \\
\hline Step 13 & $2.72 \pm 0.67$ & $2.95 \pm 0.22$ & $3.00 \pm 0.00$ & 0.008 \\
\hline Step 14 & $2.12 \pm 0.99$ & $2.65 \pm 0.73$ & $2.57 \pm 0.74$ & 0.011 \\
\hline
\end{tabular}

This result is approved by Hadgu, he found $76.5 \%$ of sample press the skin without massage (Hadgu, 2015). According to general information about diabetes, the study indicates their different answers between the three tests. Before implementation of the education program, a pre - test administrated to the adolescents who were involved in the study. Scores of pre - test $2.78 \pm 0.22$, after education program increased scores $2.93 \pm 0.10$ It means the education program has a positive effect on adolescents' knowledge concerning general information about diabetes. Post- test II was applied after two weeks. Feedback detects that adolescents knowledge is a little declining. Regarding to Insulin shot technique, found different answers between three tests. Before implementation of the education program, a pre - test administrated to the adolescents who were involved in the study. Scores of pre - test $2.78 \pm 0.22$, after education program increased score $2.82 \pm 0.28$. Post- test II was applied after two weeks. Feedback detect that adolescents knowledge is declining. Adolescents who have showed improvement in post-test I and post- test II, with concerning to some aspects insulin shot technique. Increased adolescents level of knowledge is significant in some steps of insulin shot technique. This could be due to the clearness of the program. A significant relationship between pre-test, post-test I and post-test II scores of adolescents knowledge about insulin shot technique and family income, respectively and no relation among these tests and other demographic characteristics of age, gender, residency area, level of education, number of family and child order to the family. This result can be interpreted by a good family income determining the social class of family and provides a good chance to get more information about phenomena. 


\section{Conclusion}

The study findings have provided evidence that patients should have well-information on the issue of insulin shot technique. The study indicates that the insulin administration educational program has had a positive effect on patient's knowledge related to insulin shot technique.

The level of education has made a positive influence on the patient knowledge regarding insulin shot technique issue only.

\section{References}

Al-Basra Health Directorate, 2010.

American diabetes Association. 2004. Insulin Administration, Diabetes Care, Vol. 27, Supplement 1.

American Diabetes Association. 2016. Living with diabetes - treatment and care - medication.

American diabetic association. 2012. Prevalence rates of Diabetes mellitus United states of America.

Canadian Diabetes Association. 2016. Prevalence rate in Canadian.

Cooke, D.W., Plotnick, L. 2008. Type 1 diabetes mellitus in pediatrics, $\mathrm{p} 29$.

Davel, H., Berg, G.I., Allie, R., et al. 2014. Injection technique guideline for Diabetes: sharp and to the point. JEMDSA, 19(1): 8-13.

Devendra, D., Liu, E., Eisenbarth, G.S. 2004. Type 1 diabetes: recent developments. BMJ, 328: 750-754.

Encyclopedia \& dictionary of medicine, Nursing, \&Allied Health, 6th ed new york, USA, P: 503, 505.

Hazavehei, S.M., Sharifirad, G., Mohebi, S. 2007. The effect of educational program based on health belief model on diabetic foot care. Int. J. Diabetes Dev. Ctries., 27: 18-23.

http://www.webmd.com/diabetes/guide/types-ofdiabetes-mellitus

International diabetes federation. 2010. Prevalence rate of diabetes in Arab gulf countries.

International Diabetes Federation. Prevalence rate of diabetes. 2016. p. 13.Retrieved 21 Mar 2016.

Joslin Diabetes Center. Managing Diabetes: What is Insulin Resistance? http://www.joslin.org/info/what_is_insulin_resistan ce.html.

Kertes, P.J., Johnson, T.M. 2007. Evidence Based Eye Care, Philadelphia, PA: Lippincott Williams \& Wilkins.
Lewis, P., Rowland, Timothy, A., Pedley. Merritt's Neurology, Lippincott Williams \& Wilkins. pp. 369-370.

Lorenzo, C., Williams, K., Hunt, K.J., et al. 2007. The National Cholesterol Education Program Adult Treatment Panel 111, International Diabetes Federation, and World Health Organization Definitions of the Metabolic Syndrome as Predictors of Incident Cardiovascular International Diabetes Federation (IDF).

Mastrandrea, Yu, J., Behrens, T., et al. 2009.Etanercept treatment in children with new-onset type 1 diabetes: pilot randomized, placebo-controlled, double-blind study. Diabetes Care, 32: 1244 -1249.

Naglaa, M., Abdo, Mohamed, E., Mohamed. 2010. Effectiveness Of Health Education Program For Type 2 Diabetes Mellitus Patients Attending Zagazig University Diabetes Clinic, Egypt.

National Diabetes Statistics 2011".U.S. Department of Health and Human Services. Retrieved 22 April 2014.

Neelammakol, Manisha. 2008. Diabetes an emerging health problem in India. Health action, Nov 4(10): 4,5,14,16.

Njolstad, P.R., Sagen, J.V., et al. 2003. Permanent neonatal diabetes caused by glucokinase deficiency: inborn error of the glucose-insulin signaling pathway. Diabetes, 52(11): 2854-60.

Peter. H. 2010. Chase Catherine Suffoletta: Medications: Insulin mixing and administration, chapter 9, PP.8084.

Prasad, R. Innovate for Diabetes in India. Available from:

http://blogs.novonordisk.com/graduates/2010/10/27/ innovate-for-diabetes-in-india/[Last accessed on 2012 June 01

Richard Dolinar. 2009. The Importance of Good Insulin Injection Practices in Diabetes Management. DOI: 10.17925/USE, 05.1.49.

Risérus, U., Willett, W.C., Hu, F.B. 2009. Dietary fats and prevention of type 2 diabetes, p.p 44-51.

Royal college of nursing, 2012. Starting injectable treatment in adults with type 2 diabetes.

Sanjay Kalra Yatan Pal Singh Balhara, et al. 2012. Forum for injection techniques, India: The first Indian recommendations for best practice in insulin injection technique, Volu.16, Issue 6, P. 876-885.

Sociedade Brasileira de Diabetes. Diretrizes da SBD. Tratamento e acompanhamento do diabetes mellitus. Aplicação de insulina. Rio de Janeiro, p.136-39. 
Souza, C.R., Zanetti, M.L. 2000. Administration of Insulin and Education on Diabetics. Enfermagan USP, 34(3): 264-70.

Terri Kyle and Susan Carman. 2013. Essentials of pediatric nursing, 2nd edition, p1241.

Terri Kyle Susan Carman. 2013. Essentials of pediatric nursing, 2nd edition, p.1242.

Thomas, A., Buchanan \& Anny H. Xiang. 2005. Gestational diabetes mellitus, J. Clin. Investigation, volume 115 , issue 3 .

World Health Organization. 1999. Definition, diagnosis and classification of diabetes mellitus and its complications Report of a WHO Consultation. Part 1: diagnosis and classification of diabetes mellitus.

World health organization. 2006. Prevalence rate of diabetes in Iraq.

\section{How to cite this article:}

Noor Salah Shreef. 2017. Effectiveness of Educational Program on Diabetic Adolescents Knowledge toward Selfinsulin Shot Technique in AL- Fahiaa Specialist Center at Al- Basra City. Int.J.Curr.Res.Aca.Rev. 5(3), 1-10.

doi: https://doi.org/10.20546/ijcrar.2017.503.001
World Health Organization. 2012. Type 1 diabetes.

World Health Organization. 2013. Prevalence in the world.

World health organization. 2016. Development of adolescent.

World health organization. 2016. Diabetes mellitus.

Yekta, Z., Pourali, R., Aghassi, M.R. et al. 2011. Assessment of self-care practice and its associated factors among diabetic patients in Urban Area of Urban, Northwest of Iran. J. Res. Health Sci., 11: 33-8.

Zimmet, P.Z. 1999. Diabetes epidemiology as a.tool to trigger diabetes research and care. Diabetologia, 42: 499-5. 